\title{
Testing the potential significance of different scion/rootstock genotype combinations on the ecology of old cultivated olive trees in the southeast Mediterranean area
}

\author{
Oz Barazani ${ }^{{ }^{*}} \mathbb{D}$, Yoni Waitz ${ }^{1}$, Yizhar Tugendhaft ${ }^{2,3}$, Michael Dorman $^{4}$, Arnon Dag ${ }^{2}$, Mohammed Hamidat $^{5}$, \\ Thameen Hijawi ${ }^{5}$, Zohar Kerem ${ }^{3}$, Erik Westberg ${ }^{6}$ and Joachim W. Kadereit ${ }^{6}$
}

\begin{abstract}
Background: A previous multi-locus lineage (MLL) analysis of SSR-microsatellite data of old olive trees in the southeast Mediterranean area had shown the predominance of the Souri cultivar (MLL1) among grafted trees. The MLL analysis had also identified an MLL (MLL7) that was more common among rootstocks than other MLLs. We here present a comparison of the MLL combinations MLL1 (scion)/MLL7 (rootstock) and MLL1/MLL1 in order to investigate the possible influence of rootstock on scion phenotype.

Results: A linear regression analysis demonstrated that the abundance of MLL1/MLL7 trees decreases and of MLL1/ MLL1 trees increases along a gradient of increasing aridity. Hypothesizing that grafting on MLL7 provides an advantage under certain conditions, Akaike information criterion (AIC) model selection procedure was used to assess the influence of different environmental conditions on phenotypic characteristics of the fruits and oil of the two MLL combinations. The most parsimonious models indicated differential influences of environmental conditions on parameters of olive oil quality in trees belonging to the MLL1/MLL7 and MLL1/MLL1 combinations, but a similar influence on fruit characteristics and oil content. These results suggest that in certain environments grafting of the local Souri cultivar on MLL7 rootstocks and the MLL1/MLL1 combination result in improved oil quality. The decreasing number of MLL1/MLL7 trees along an aridity gradient suggests that use of this genotype combination in arid sites was not favoured because of sensitivity of MLL7 to drought.
\end{abstract}

Conclusions: Our results thus suggest that MLL1/MLL7 and MLL1/MLL1 combinations were selected by growers in traditional rain-fed cultivation under Mediterranean climate conditions in the southeast Mediterranean area.

Keywords: Akaike information criterion (AIC) selection model, Environmental conditions, Multi-locus lineage analysis, Olive oil quality, Selection

\section{Background}

The history of fruit tree domestication is strongly linked to grafting, which provided an easy technique for clonal reproduction of trees with desirable properties that are difficult to propagate vegetatively. It is generally accepted that the domestication of several fruit trees such as apple,

\footnotetext{
*Correspondence: barazani@agri.gov.il

${ }^{1}$ Institute of Plant Sciences, Israel Plant Gene Bank, Agricultural Research Organization, 75359 Rishon LeZion, Israel

Full list of author information is available at the end of the article
}

plum and others was not possible without the development of the grafting technique [1]. In addition to being useful or necessary for propagation, rootstocks can influence the size of scions and increase their vigor. Physiological investigation of the interactions between scions and rootstocks in grapevine showed that grafting can reduce the toxic effects of salinity by the ability of the rootstock to limit the uptake of $\mathrm{Na}^{+}$and $\mathrm{Cl}^{-}$ions by the scion [2]. In several crop species, e.g., in peach [3] and grapevine [4], rootstocks have been shown to reduce leaf 
chlorosis caused by iron deficiency. Rootstocks also have been selected to increase tree tolerance to abiotic stresses such as drought and soil $\mathrm{pH}[1]$, and increase the resistance against soil pathogens [5].

Genetic comparison of suckers and the canopy of old olive trees in the Iberian peninsula [6] and the southeast Mediterranean area [7] provide strong evidence for grafting as a common practice in olive cultivation in the past $[8,9]$. Diez et al. suggested that by grafting of scions on wild growing trees, natural populations of Olea europaea subsp. europaea var. sylvestris were transformed into olive groves [6], and the use of individual 'wild' olive trees as vigorous rootstocks in traditional olive cultivation has also been suggested [9]. However, evidence on the potential contribution of the rootstock to olive tree fitness and phenotypic properties is very limited and is based on recent experimental systems using combinations of known cultivars [10-13]. In these experiments, particular combinations of rootstocks and scions were shown to decrease the harmful effects of excessive boron concentrations in the soil [11], and to increase resistance to Verticillium wilt $[10,12]$.

Previously we reported that most old olive trees in the southeast Mediterranean area are grafted. In addition, a multi-locus lineage (MLL) analysis had shown that most of the scions (ca. 90\%) belong to a single MLL (MLL1), presumably representing the Souri cultivar, and that most of the rootstocks probably originated from plant individuals resulting from sexual reproduction [7]. However, we also identified an MLL (MLL7) that was more common than other MLLs in rootstocks of grafted old olive trees and was present in $23 \%$ of the trees analysed [7]. This led to the hypothesis that olive cultivation in the region may have involved selection not only of a specific scion but also of a specific rootstock. Traditional olive groves in the southeast Mediterranean area are distributed along a geographic gradient of diverse climatic, topographic and edaphic conditions $[14,15]$. As rootstocks might have been selected for improvement of the root system in stressful conditions and/or for their influence on phenotypic properties of the scion, we aimed to investigate the contribution of the most common rootstock (MLL7) to the fitness and phenotype of olive trees in different environments. We here use a model selection procedure based on the Akaike information criterion (AIC) to investigate the potential advantage of the MLL1/MLL7 combination by quantifying the impact of a number of environmental variables on several agriculturally important phenotypic traits.

\section{Methods}

In our previous study [7] we reported on a total of 249 old olive trees in which both suckers and scions were collected from the same trees and genotyped. Identification of scion and rootstock MLLs was performed with leaf samples taken from tree canopies (i.e. scions) and from suckers that developed from the trunk base [7]. Thus, a comparison between scion and sucker of the same tree enabled us to differentiate between three genetic groups (GG): 1) GG1 included trees in which the common Souri cultivar (MLL1) was grafted on MLL7 (49 trees); 2) GG2, in which both suckers and scions were assigned to MLL1 (62 trees); and 3) GG3 included those trees in which the common Souri cultivar was grafted on singleoccurrence rootstock MLLs that probably originated from sexual reproduction (117 trees). Trees of the second group (GG2) were either the result of vegetative propagation of MLL1 or of grafting of MLL1 scions on MLL1 truncheons. The analysis included a total of 228 old olive trees from 31 groves with various environmental conditions in the southeast Mediterranean area.

\section{Phenotypic characterization}

Fruits were collected during the harvest in a single season in 2008 and were used for morphological evaluation, oil extraction and evaluation of content and quality of the oil. Morphological evaluation included the weight and dimension of 10 fruits and stones of each tree. The Abencor system (MC2 Ingenieria Y Sistemas, Spain) was used to extract oil from $1 \mathrm{~kg}$ of fruits of each of the investigated trees [16], and the relative content of oil and paste water was determined after Soxhlet chemical extraction as previously described [17]. Fatty acid (FFA) profiles were determined following [18], and the ratio between monounsaturated fatty acids (MUFA) and polyunsaturated fatty acids (PUFA) was determined. Following BenGal et al. [18], the peroxide value (milliequivalents of active oxygen per kilogram oil; mequiv $\left.\mathrm{kg}^{-1}\right)$, acidity (\% free oleic acid) and total content of polyphenols ( $\mathrm{mg} \mathrm{kg}^{-1}$ oil) in the oil were also determined.

\section{Environmental parameters}

Average annual rainfall and elevation data were gathered from the Geographic Information System center database (Hebrew University of Jerusalem) using the lati-/ longitudinal coordinates of groves. Daily temperatures for 2008 were collected using the MODIS remote sensing of surface and canopy temperatures (http://modis-land. gsfc.nasa.gov/); $T_{\max }$ and $T_{\min }$ were calculated according to Blum et al. [19] and used to determine the number of growing degree days (GDD) during the period from first flowering to fruit harvest (mid-April to mid-November), following the equation $\left.\frac{T_{\max }+T_{\min }}{2}-T_{\text {base }}\left(9.1{ }^{\circ} \mathrm{C}\right)[20]\right)$. Calcium carbonate content in the soil was used to assess edaphic conditions, as calcareous soil is one of the limiting factors of agricultural practice in the region [15]. Soil samples, five in each grove, were collected from 
three soil depths $(0-30,30-60$ and $60-90 \mathrm{~cm})$, and soil analysis was conducted by the Gilat Extension Services Laboratory and Research Center (Israel); the results are presented as the average value of the three layers analysed $\left(\%\right.$ of $\left.\mathrm{CaCO}_{3}\right)$.

\section{Statistical analysis}

Linear regression was used to examine the abundance of trees belonging to the two scion/sucker combinations MLL1/MLL7 (GG1) vs. MLL1/MLL1 (GG2) along gradients of environmental conditions. Linear models were also used to examine which environmental factors explain phenotypic variation. To evaluate the environmental effects, we used a model selection procedure based on the Akaike information criterion (AIC), corrected for small sample sizes [21]. Models where the given trait (e.g. oil content, peroxide value, etc.) was explained using all possible combinations of environmental factors (e.g. GDD, $\mathrm{CaCO}_{3}$, etc.), genetic groups (GG1 vs. GG2) and the interactions of each environmental factor with genetic groups were evaluated based on AIC. Old olive trees belonging to GG3 were not included in the AIC analysis as they do not represent a genetically homogenous group. The AIC analysis thus included a total of 111 trees. Factors present in the most parsimonious model (i.e. with the lowest AIC) and their direction of influence were then summarized. The inclusion of interaction terms enabled us to understand whether the genetic groups (GG1 in comparison to GG2) differ in their response to the different environmental factors (i.e. presence of a genotype-by-environment interaction). All statistical analyses were done using $\mathrm{R}$ [22].

\section{Results}

\section{The abundance of olive trees with different genotype} combinations in groves along environmental gradients

Traditional rain-fed olive groves in the southeast Mediterranean area are scattered through geographical districts that vary in climatic conditions and soil texture and chemistry. For this study, olive groves were selected to represent an aridity gradient from north to south, ranging from relatively mesic Mediterranean climate sites ( $\geq 450 \mathrm{~mm}$ rainfall) to semi-arid $(350-450 \mathrm{~mm}$ ) and arid conditions with less than $<350 \mathrm{~mm}$ rainfall per year (ASH) (Table 1, Fig. 1). We included groves of relatively high elevation in the Samaria and Judean Mts. (440 to ca. $720 \mathrm{~m}$ a.s.l.) to lower elevation in the inner plain (110$290 \mathrm{~m}$ a.s.l.), the Carmel and the coastal plain (MAK, $84 \mathrm{~m}$ a.s.l. and ASH $23 \mathrm{~m}$ a.s.l., respectively). Variation in the average annual maximum and minimum temperatures (expressed as growing-degree day, GDD) was also found among sites. The range of $\mathrm{CaCO}_{3}$ content in the soil $(2.0-57.7 \%)$ represents the variability of edaphic conditions in the region (Table 1). Linear regression did not show any significant correlation between any of the environmental parameters (data not shown).

Mapping the relative number of trees of all three MLL combinations in the investigated groves showed that trees of the MLL1/MLL7 combination (GG1) are more abundant in the northern (Galilee) and central parts (Samaria and Judean Mts.) of the cultivation area of olives in the southeast Mediterranean area (Fig. 1). The linear regression showed a significant association between average rainfall and the proportion of trees belonging to GG1 $\left(F_{1,29}=7.068, P=0.0126\right)$ and those of GG2 $\left(F_{1,29}=6.929, P=0.0135\right)$, but this proportion was not associated with any of the other environmental parameters considered, i.e. GDD, elevation ( $m$ a.s.l) and the relative content of $\mathrm{CaCO}_{3}$ in the soil (Table 2). As expected when estimating the effect of single environmental factor in ecological studies, the significant association between average rainfall and the proportion of GG1 and GG2 trees $\left(R^{2}=0.19\right)$ suggests that other unknown environmental factor(s) contribute to the abundance of these two MLL combinations along the aridity gradient. Nevertheless, the abundance of trees of GG1 was higher at more mesic locations, while the proportion of trees belonging to GG2 increased with increasing aridity (Fig. 2).

\section{Testing the potential contribution of genotype combination to tree phenotype}

ANOVA post hoc tests did not show significant differences between trees belonging to the GG1 and GG2 combinations in any of the eight phenotypic traits measured (Additional file 1: Figure S1, Additional file 2: Table S1). When taking into account environmental effects and genetic group in the AIC model selection procedure, the content of paste water in the fruit, the peroxide value and stone length were positively associated with grafting, while the ratio of MUFA/PUFA and stone width were negatively influenced by grafting of MLL1 on MLL7 (Table 3). Note that the use of positive or negative 'influence' or 'effect' refers to their statistical term in the model, and thus does not necessarily reflect beneficial (positive) or detrimental (negative) effects. Our results further showed that the environmental parameters influenced most of the fruit traits of GG1 and GG2 trees in a similar way (Table 3 and Additional file 3). Exceptions to this were the positive effects of elevation and $\mathrm{CaCO}_{3}$ content on paste water and peroxide value in trees of GG1, respectively, and the negative effects of these environmental parameters on these traits in trees of GG2. Oil content and fruit and stone dimension and weight were positively influenced by average rainfall in both GG1 and GG2 trees. Similar negative effects of average rainfall were found in acidity and paste water content, while 
Table 1 Environmental data of the investigated groves arranged along an aridity gradient; GDD data for ASH is missing

\begin{tabular}{|c|c|c|c|c|c|c|}
\hline & Geographic region & $\mathrm{CaCO}_{3}(\%)$ & Soil type & GDD & Average annual rainfall $(\mathrm{mm})$ & Elevation ( $m$ a.s.l.) \\
\hline YRM & Galilee & 25.67 & Terra Rosa & 3365 & 324.90 & 341.67 \\
\hline YRR & Galilee & 25.67 & Terra Roas & 3365 & 324.90 & 341.67 \\
\hline RAl & Galilee & 2.00 & Terra Rosa & 3655 & 391.60 & 379.92 \\
\hline RAR & Galilee & 2.67 & Terra Rosa & 3736 & 391.60 & 347.13 \\
\hline ZAL & Galilee & 4.33 & Terra Rosa & 4002 & 391.60 & 92.69 \\
\hline $\mathrm{DIH}$ & Galilee & 34.00 & Terra Rosa & 3769 & 391.60 & 385.75 \\
\hline KAM & Galilee & 18.67 & Terra Rosa & 3631 & 391.60 & 329.75 \\
\hline KZE & Galilee & 8.00 & Heavy soil & 4014 & 391.60 & 111.38 \\
\hline MAK & Carmel & 14.00 & Terra Rosa & 3425 & 388.90 & 84.27 \\
\hline EJB & Samaria & 57.67 & Terra Rosa & 2861 & 317.50 & 248.49 \\
\hline ETS & Samaria & 28.33 & Rendzina & 3745 & 454.50 & 242.04 \\
\hline EWIK & Samaria & 37.00 & Terra Rosa & 3738 & 454.50 & 339.05 \\
\hline ETD & Samaria & 45.33 & Terra Rosa & 3786 & 454.50 & 337.72 \\
\hline EQA & Samaria & 55.33 & Terra Rosa & 3573 & 408.10 & 286.00 \\
\hline ENZ & Samaria & 48.67 & Terra Rosa & 3446 & 356.10 & 373.01 \\
\hline ENB & Samaria & 37.67 & Heavy soil & 2481 & 356.10 & 522.56 \\
\hline ESB & Samaria & 38.67 & Terra Rosa & 3372 & 408.10 & 289.72 \\
\hline ESK & Samaria & 41.00 & Terra Rosa & 3124 & 408.10 & 337.72 \\
\hline ERK & Samaria & 38.00 & Rendzina & 2709 & 466.10 & 460.75 \\
\hline HAD & Inner plain & 35.33 & Rendzina & 3821 & 276.00 & 111.17 \\
\hline ERB & Judean Mts & 54.33 & Rendzina & 3334 & 466.10 & 439.33 \\
\hline EJBA & Judean Mts. & 33.67 & Terra Rosa & 2650 & 382.90 & 575.53 \\
\hline JER & Judean Mts. & 46.00 & Terra Rosa & 4077 & 353.40 & 723.71 \\
\hline EIK & Judean Mts. & 15.33 & Terra Rosa & 3297 & 382.90 & 630.54 \\
\hline YAL & Judean Mts. & 38.67 & Terra Rosa & 3350 & 287.10 & 615.27 \\
\hline EBB & Judean Mts. & 33.00 & Terra Rosa & 2133 & 359.70 & 726.96 \\
\hline AZK & Inner plain & 39.33 & Rendzina & 3650 & 320.40 & 272.65 \\
\hline BNR & Inner plain & 24.33 & Rendzina & 3714 & 320.40 & 292.64 \\
\hline EHS & Judean Mts. & 25.33 & Terra Rosa & 2898 & 301.40 & 547.66 \\
\hline ASH & Coastal plain & 34.33 & Sand & - & 193.90 & 23.65 \\
\hline AMZ & Inner plain & 42.00 & Rendzina & 3608 & 344.50 & 328.08 \\
\hline
\end{tabular}

the average rainfall did not have any effect on the other oil quality characters in the two groups of trees (i.e. total polyphenol concentration, peroxide values and MUFA/ PUFA). Elevation had a stronger effect on MUFA/PUFA in trees of the GG1 combination than in those belonging to GG2 and on peroxide values in GG2 trees than in trees of GG1. Similarly, $\mathrm{CaCO}_{3}$ had a stronger influence on stone weight in GG1 trees and on stone length in trees belonging to GG2. GDD had a positive effect on peroxide values in both groups of trees, but its effect was more pronounced in trees of GG2. In addition, the negative effect of GDD on stone weight was stronger in trees belonging to GG1 than in those belonging to GG2. The adjusted $R^{2}$ values of the AIC model showed the lowest value for total concentration of polyphenols (0.03) and the highest for peroxide value $(0.40)$ and stone weight (0.55) (Table 3 and Additional file 3).

\section{Discussion}

Old olive trees in the southeast Mediterranean area that belong to the common Souri cultivar have rootstocks of different genotype (MLL). Our previous results indicated that $23 \%$ of the rootstocks belong to one multi-locus lineage (i.e. MLL7) [7]. Mapping of the trees in which the local MLL1 variety is grafted on the common MLL7 (GG1), and those in which scion and suckers both belong to MLL1 (GG2) showed that the first group of trees (GG1) are more abundant in the northern and central parts of the olive cultivation area in the region (Fig. 1). In addition, the linear regression analysis indicated a significant association between the relative number of GG1 trees at each grove and the average annual precipitation (Fig. 2). Thus, old olive trees growing in groves with different environmental conditions (Table 1), but with the same MLL in their fruit bearing part (MLL1) and with 


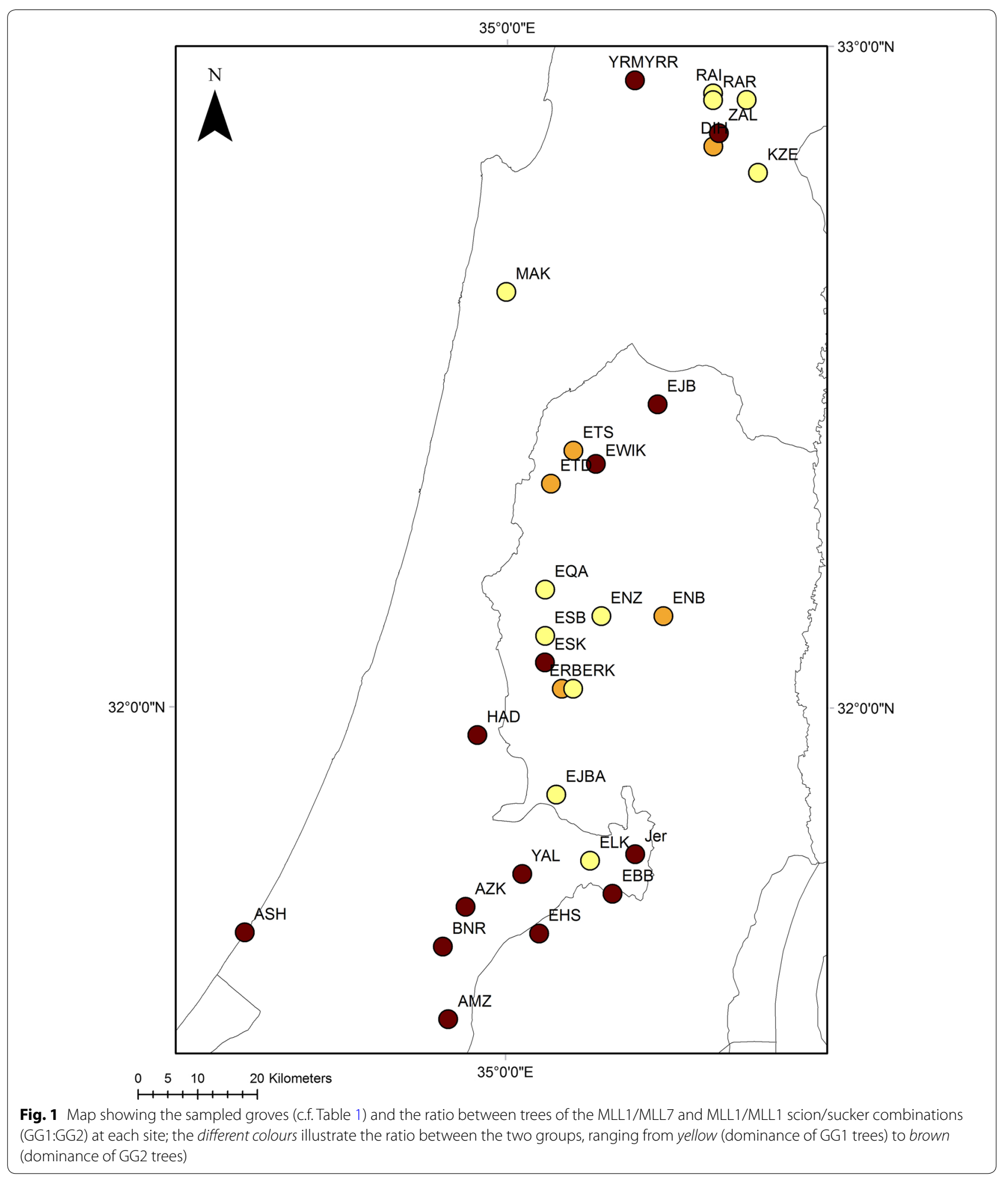

rootstocks belonging to either MLL1 or MLL7, offer an opportunity to examine the possible contribution of the rootstock to traits of the crop, which more commonly is studied in common garden experiments.
Our sampling included trees growing in a range of soils that vary in their $\mathrm{CaCO}_{3}$ content (2.0-57.7\%) (Table 1). It has been suggested that grafting of olives is recommended for growing trees in problematic soils, such as 
Table 2 Linear regression between environmental parameters and the relative number of old olive trees belonging to GG1 and GG2

\begin{tabular}{lllllll}
\hline & GG1 & & & & GG2 & \\
\cline { 2 - 3 } & $\boldsymbol{R}^{\mathbf{2}}$ & $\boldsymbol{F}_{1,29}$ & $\boldsymbol{P}$ & & $\boldsymbol{R}^{\mathbf{2}}$ & \multicolumn{1}{c}{$\boldsymbol{F}_{\mathbf{1 , 2 9}}$} \\
\hline Average rainfall & 0.1960 & 7.0680 & 0.0126 & 0.1928 & 6.9290 \\
Elevation & $4.26 \times 10^{-5}$ & 0.0012 & 0.9722 & 0.1148 & 3.7610 & 0.0135 \\
GDD & 0.01120 & 0.3285 & 0.5710 & 0.0061 & 0.1716 & 0.6818 \\
Calcium & 0.07734 & 2.4310 & 0.1298 & 0.0211 & 0.6257 & 0.4353 \\
\hline
\end{tabular}
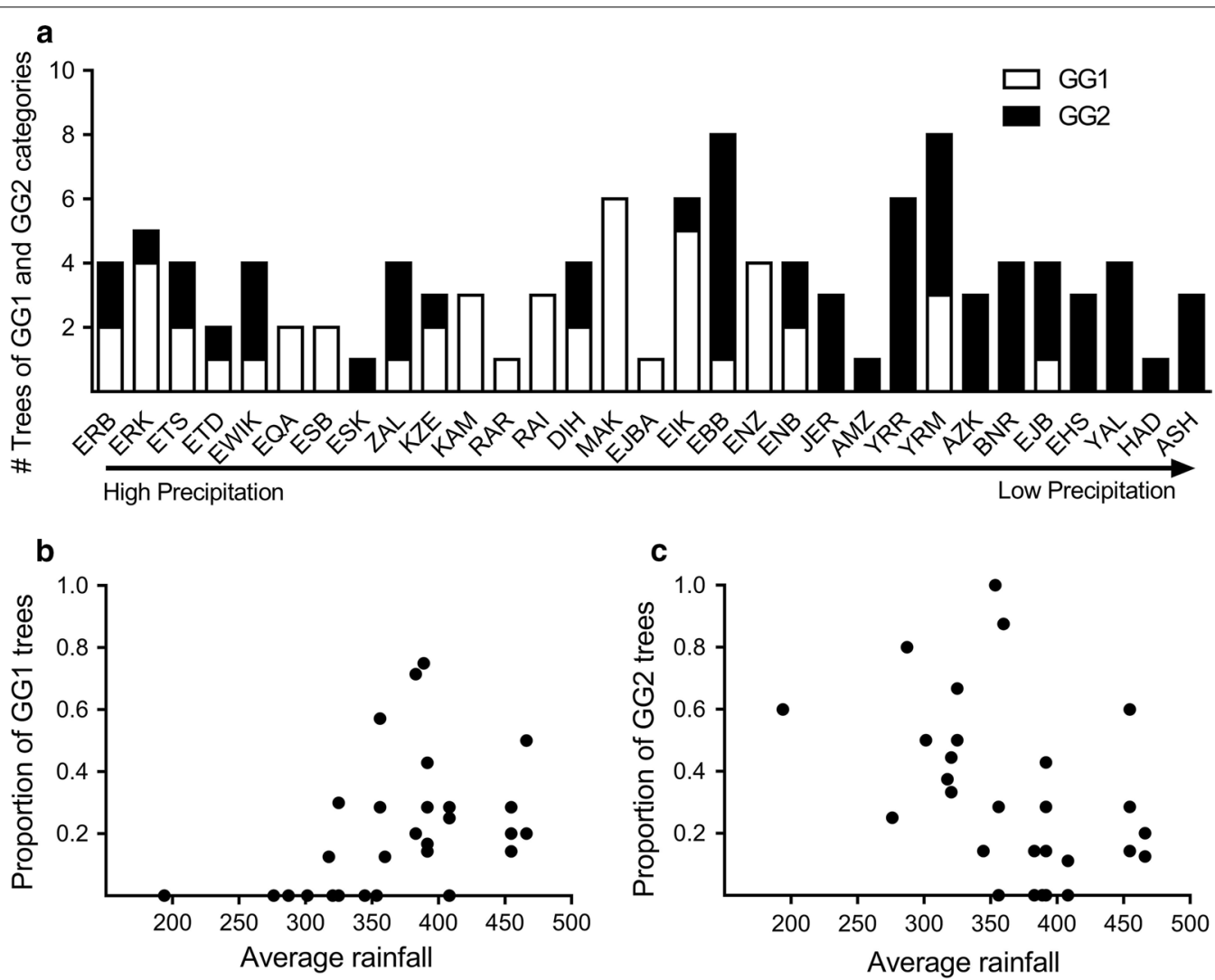

Fig. 2 Relative proportions of trees belonging to GG1 and GG2 along an aridity gradient showing the predominance of trees of GG1 in groves in geographic locations with relatively higher average annual rainfall and their absence from the driest groves $(\mathbf{a})$. Relation between average annual rainfall and the proportion of trees of GG1 (b) and GG2 (c); the relative number of trees was calculated from the total number of trees at each site (i.e. including all three categories: GG1, GG2 and GG3)

soils with high $\mathrm{CaCO}_{3}$ contents or saline soils [13]. We thus hypothesized that grafting on the specific MLL7 can provide an advantage in the calcareous soils of the region, where soil $\mathrm{pH}$ is high and availability of water and micronutrients is limited [15]. Supporting this hypothesis, the AIC model selection procedure showed differential positive and negative responses of peroxide values to the effect of $\mathrm{CaCO}_{3}$ in GG1 and GG2 trees, respectively
(Table 3). Also, a strong positive influence of elevation on the oleic acid content in the oil, and thus on MUFA/ PUFA, of GG1 trees in comparison with GG2 trees was found (Table 3). As peroxides are produced from the oxidation of fatty acids, high levels of peroxide are undesirable, causing rancid taste and reducing the oil shelf-life [23]. Equally, oleic acid (MUFA) is a major determinant of mouth-feel, aroma and shelf life of olive oil [24]. As 
Table 3 Predicted direction of influence for the effects of environmental variables on the phenotypic traits of the investigated trees belonging to GG1 and GG2; model summaries are provided in Additional file 3

\begin{tabular}{|c|c|c|c|c|c|c|c|c|c|c|}
\hline & \multirow[t]{2}{*}{$\mathrm{GG} 1^{\mathrm{a}}$} & \multicolumn{2}{|c|}{$\begin{array}{c}\text { Average } \\
\text { rainfall }\end{array}$} & \multicolumn{2}{|c|}{ Elevation } & \multicolumn{2}{|c|}{$\mathrm{CaCO}_{3}$} & \multicolumn{2}{|c|}{ GDD } & \multirow[t]{2}{*}{ Adjusted $R^{2}$} \\
\hline & & GG1 & GG2 & GG1 & GG2 & GG1 & GG2 & GG1 & GG2 & \\
\hline Oil content & & + & + & & & + & + & - & - & 0.21 \\
\hline Paste water & + & - & - & + & - & - & - & & & 0.45 \\
\hline Acidity value & & - & - & + & + & - & - & + & + & 0.22 \\
\hline Peroxide value & + & & & + & ++ & + & - & + & ++ & 0.40 \\
\hline Polyphenols conc. & & & & - & - & & & - & - & 0.03 \\
\hline MUFA/PUFA & - & & & ++ & + & & & + & + & 0.08 \\
\hline Stone weight & - & + & + & & & ++ & + & -- & - & 0.55 \\
\hline Stone length & + & + & + & & & + & ++ & - & - & 0.17 \\
\hline Stone width & & + & + & + & + & + & + & - & - & 0.22 \\
\hline Fruit weight & & + & + & + & + & & & & & 0.06 \\
\hline Fruit width & & + & + & & & & & - & - & 0.08 \\
\hline
\end{tabular}

Positive and negative association is given by the coefficients of the most parsimonious model (Additional file 3 ) for the given trait as either positive ( + green cells), negative ( - red cells) or zero (blank grey cells; when the variable was not present in the final model). Interaction between genotype combination and environmental effects is indicated by the differences between the two columns for a given environmental variable. For example, the effect of $\mathrm{CaCO}_{3}$ on peroxide value is positive in GG1 but negative in GG2 due to the presence of an interaction term in the final model

* Results of general linear model explaining the effect of genotype combination on phenotypic traits

both taste and shelf life are likely to have been quality criteria important for early farmers, our results, showing differential responses of the two groups of scion/sucker combination in peroxide values and oleic acid contents, suggest a potential contribution of the MLL7 rootstock to olive oil quality under different edaphic conditions.

Results of the AIC-based model selection indicated that all environmental parameters in general had a similar influence on fruit and stone size and weight, and hence on oil content in the fruits, in the two genotype combinations (Table 3). In addition, average rainfall influenced the quality traits (as well as all other phenotypic characters) in GG1 and GG2 trees in a similar way (zero, positive or negative). However, elevation as well as GDD had a stronger positive influence on peroxide values in GG2 than in GG1 trees, and elevation had stronger positive effect on the MUFA/PUFA ratio in GG1 trees as compared to GG2 trees (Table 3). Thus these results provided further evidence, in addition to the effect of elevation and $\mathrm{CaCO}_{3}$ described above, that some environmental parameters have a differential influence on oil quality in GG1 vs. GG2 trees. The decreasing abundance of trees belonging to GG1 (i.e. common MLL1 grafted on MLL7) along an aridity gradient (Fig. 2) may imply that grafting on MLL7 may increase sensitivity of olive trees to drought. Support of this hypothesis may be provided by a recent study which showed that young trees that were produced from the common MLL1 showed higher drought tolerance than trees of the Barnea cultivar (no comparison with MLL1/MLL7 was made), suitable for intensive agricultural conditions based on controlled irrigation [25].

\section{Conclusions}

Overall, our results seem to imply that grafting of the common Souri cultivar (MLL1) on the MLL7 rootstock was governed by two opposing forces. On the one hand, growers in the past may have chosen to graft the common cultivar (MLL1) on MLL7 in order to enhance crop performance under certain environments. As MLL7 was used for grafting much more commonly than other MLLs [7], it appears that not grafting alone but grafting on MLL7 has this positive effect, which suggests deliberate rootstock selection. On the other hand, this advantage of grafting on MLL7 is countered by the plausible sensitivity of MLL7 to drought, so that this rootstock was less used in increasingly arid environments. If the scion/rootstock combination MLL1/MLL1 should represent non-grafted trees, it could be concluded that the grafting technique itself was less used in arid environments. Recent studies that assessed oil quality of the Souri cultivar under different irrigation regimes demonstrated the better performance of the cultivar under rain-fed condition [26, 27]. As these oil quality traits reflect the nutritional value of the olive oil, its taste and oxidative status [23, 24], it seems that the scion/rootstock combination MLL1/ MLL7 was ideally adapted to conditions in a southeast Mediterranean climate. 


\section{Additional files}

Additional file 1: Figure S1. Box plot comparisons of phenotypic traits in old olive trees of the MLL1/MLL7 (GG1) and MLL1/MLL1 (GG2) scion/ sucker combinations. Traits included the oil content in the fruits, waste water content obtained in the oil extraction process, four oil quality characteristics and three morphological properties of the fruits and stones.

Additional file 2: Table S1. Quantitative phenotypic data for each tree belonging to $\mathrm{GG1}$ and $\mathrm{GG} 2$; $\mathrm{md}$ represent missing data.

Additional file 3. Results of the model-selection procedure.

\section{Abbreviations}

AIC: Akaike information criterion; FFA: free fatty acid; GDD: growing degree days; GG: genetic group; MLL: multi-locus lineage; MUFA: monounsaturated fatty acids; PUFA: polyunsaturated fatty acids; SSR: simple sequence repeats.

\section{Authors' contributions}

$\mathrm{OB}, \mathrm{AD}, \mathrm{ZK}, \mathrm{TH}$ and JWK conceived this study. YT and MH collected the samples and performed the phenotypic characterization. EW conducted the genetic analysis. YW and MD conducted the statistical analysis. OB and JWK wrote the manuscript with contributions from all co-authors. All co-authors approved submission to BMC Ecology. All authors read and approved the final manuscript.

\section{Author details \\ ${ }^{1}$ Institute of Plant Sciences, Israel Plant Gene Bank, Agricultural Research Organization, 75359 Rishon LeZion, Israel. ${ }^{2}$ Department of Fruit Tree Sciences, Institute of Plant Sciences, Agricultural Research Organization, Gilat Research Center, 85280 M.P. Negev 2, Israel. ${ }^{3}$ Institute of Biochemistry, Food Science and Nutrition, Faculty of Agricultural, Food and Environmental Quality Sci- ences, The Hebrew University of Jerusalem, 76100 Rehovot, Israel. ${ }^{4}$ Depart- ment of Geography and Environmental Development, Ben-Gurion University of the Negev, 84105 Beer-Sheva, Israel. ${ }^{5}$ Arab Agronomist Association, Al Nahda St., Ramallah and Al-Bireh Governorate, 4504 Al-Bireh, Palestine. ${ }^{6}$ Institut für Spezielle Botanik und Botanischer Garten, Johannes Gutenberg- Universität Mainz, 55099 Mainz, Germany.}

\section{Acknowledgements}

We thank all farmers who allowed us to sample trees in their orchards. We also thank Mr. I. Zipori for his valuable contribution to this study.

\section{Competing interests}

The authors declare that they have no competing interests.

\section{Availability of data and materials}

All relevant data supporting our findings is provided in the article and supporting information. Results of our previous SSR analysis of grafted old olive trees can be found in BMC Plant Biol (2014), 14:146.

\section{Ethics}

For issues concerning ethics, please refer to our previous publications: Barazani et al. [7] BMC Plant Biology 14: 146; Barazani et al. [28] BMC Plant Biology 16: 261.

\section{Funding}

This study was partially supported by the German Research Foundation's (DFG) trilateral program (Grant No. KA 635/14).

Received: 19 September 2016 Accepted: 16 January 2017 Published online: 06 February 2017

\section{References}

1. Mudge K, Janick J, Scofield S, Goldschmidt EE. A history of grafting. In: Janick J, editor. Horticultural reviews, vol. 35. Hoboken:Wiley; 2009. p. 437-93.
2. Dag A, Ben-Gal A, Goldberger S, Yermiyahu U, Zipori I, Or E, David I, Netzer $Y$, Kerem Z. Sodium and chloride distribution in grapevines as a function of rootstock and irrigation water salinity. Am J Enol Viticult. 2015;66:80-4.

3. Sotomayor C, Ruiz R, Castro J. Growth, yield and iron deficiency tolerance level of six peach rootstocks grown on calcareous soil. Cienc Investig Agrar. 2014;41:403-9.

4. Covarrubias Jl, Retamales C, Donnini S, Rombola AD, Pastenes C. Contrasting physiological responses to iron deficiency in Cabernet Sauvignon grapevines grafted on two rootstocks. Sci Horticulturae. 2016;199:1-8.

5. King SR, Davis AR, Liu WG, Levi A. Grafting for disease resistance. HortScience. 2008:43:1673-6.

6. Diez CM, Trujillo I, Barrio E, Belaj A, Barranco D, Rallo L. Centennial olive trees as a reservoir of genetic diversity. Ann Bot. 2011;108:797-807.

7. Barazani O, Westberg E, Hanin N, Dag A, Kerem Z, Tugendhaft Y, Hmidat M, Hijawi T, Kadereit JW. A comparative analysis of genetic variation in rootstocks and scions of old olive trees - a window into the history of olive cultivation practices and past genetic variation. BMC Plant Biol. 2014;14:146.

8. Foxhall L. Olive cultivation in ancient Greece: seeking the ancient economy. Oxford: Oxford University Press; 2007.

9. Zohary D, Hopf M. Domestication of plants in the old world. 2nd ed. Oxford: Oxford Science Publications, Claredon Press; 1994.

10. Bubici G, Cirulli M. Control of Verticillium wilt of olive by resistant rootstocks. Plant Soil. 2012;352:363-76.

11. Chatzissavvidis C, Therios I, Antonopoulou C, Dimassi K. Effects of high boron concentration and scion-rootstock combination on growth and nutritional status of olive plants. J Plant Nutr. 2008;31:638-58.

12. Soriano A, Martin M, Piedra A. Grafting olive cv. Cornicabra on rootstocks tolerant to Verticillium dahliae reduces their susceptibility. Crop Prot. 2003;22:369-74.

13. Therios I. Olives, vol. 18. Wallingford: CABI; 2009.

14. Goldreich Y. The climate of Israel: observation, research and application. New York: Springer; 2003.

15. Singer A. The Soils of Israel. Berlin: Springer; 2007.

16. Ben-David E, Kerem Z, Zipori I, Weissbein S, Basheer L, Bustan A, Dag A. Optimization of the Abencor system to extract olive oil from irrigated orchards. Eur J Lipid Sci Tech. 2010;112:1158-65.

17. Dag A, Kerem Z, Yogev N, Zipori I, Lavee S, Ben-David E. Influence of time of harvest and maturity index on olive oil yield and quality. Sci Horticulturae. 2011;127:358-66.

18. Ben-Gal A, Dag A, Basheer L, Yermiyahu U, Zipori I, Kerem Z. The influence of bearing cycles on olive oil quality response to irrigation. J Agr Food Chem. 2011;59:11667-75.

19. Blum M, Lensky IM, Nestel D. Estimation of olive grove canopy temperature from MODIS thermal imagery is more accurate than interpolation from meteorological stations. Agr For Meteorol. 2013;176:90-3.

20. Snyder RL. Hand calculating degree days. Agr For Meteorol. 1985;35:353-8.

21. Johnson JB, Omland KS. Model selection in ecology and evolution. Trends Ecol Evol. 2004;19:101-8.

22. R Core Team: R. A language and environment for statistical computing. R Foundation for Statistical Computing. In Vienna. https://www.R-project. org/; 2016.

23. Mariotti M. Virgin olive oil: definition and standards. In: Peri C, editor. The extra-virgin olive oil handbook. Chichester: Wiley; 2014. p. 11-9.

24. Mariotti M, Peri C. The composition and nutritional properties of extravirgin olive oil. In: Peri C, editor. The extra-virgin olive oil handbook. Chichester: Wiley; 2014. p. 21-34.

25. Tugendhaft Y, Eppel A, Kerem Z, Barazani O, Ben-Gal A, Kadereit JW, Dag A. Drought tolerance of three olive cultivars alternatively selected for rain fed or intensive cultivation. Sci Horticulturae. 2016;199:158-62.

26. Ben-Gal A, Dag A, Yermiyahu U, Tsipori I, Presnov E, Faingold I, Kerem A. Evaluation of irrigation in a converted, rain fed olive orchard: the transition year. Acta Hortic. 2008;792:99-106.

27. Dag A, Ben-Gal A, Yermiahu U, Basheer L, Yogev N, Kerem Z. The effect of irrigation level and harvest mechanization on virgin olive oil quality in a traditional rain-fed 'Souri' olive orchard converted to irrigation. J Sci Food Agric. 2008;88:1524-8.

28. Barazani O, Keren-Keiserman A, Westberg E, Hanin N, Dag A, Ben-Ari G, Fragman-Sapir O, Tugendhaft Y, Kerem Z, Kadereit JW. Genetic variation of naturally growing olive trees in Israel: from abandoned groves to feral and wild? BMC Plant Biol. 2016;16:261. 